\title{
The Effect of Different Growing Medium Combination on Growth and Yield of Boesenbergia rotunda
}

\author{
Nasiroh Md Nasir, Rozilawati Shahari*, Nur Shuhada Muhamad Tajudin \\ Department of Plant Science, Kulliyyah of Science, International Islamic University Malaysia, Pahang, Malaysia. \\ Corresponding Author Email: firdawila@iium.edu.my
}

\section{Doi: 10.2478/mjhr-2020-0007}

\begin{abstract}
:
Boesenbergia rotunda or Temu kunci is a herb belonging to the Zingiberaceae family and wildly cultivated in Malaysia by rhizome. Temu kunci rhizome is commonly used in traditional medicines to cure stomach aches, promote appetite and gout. Due to its potential to be developed as one of Malaysia's herbal products, information on their agronomic requirements is needed. This study was conducted to investigate the effects of the different combination of the growing medium on B. rotunda growth and yield. Topsoil, peat moss, sand and chicken manure with four different ratios have been used as a planting medium. The potted plant was arranged in a randomised, complete block design with five replicates. The growth parameter was measured during harvesting time. The results showed that there was no significant difference in plant height, number of leaves, tiller number, fresh and dry shoot weight and fresh and dry root and rhizome weight in all treatments. It can be argued that this is because B. rotunda can be grown in different kinds of planting medium. Based on this study, it was suggested that topsoil be used for Temu Kunci planting, since it is easily obtained and requires less money.
\end{abstract}

Keywords: Growing medium, growth, yield, Boesenbergia rotunda

\subsection{Introduction:}

People have always used herbs as a condiment in cooking to enhance the flavour and aroma of food. Besides being eaten raw as ulam, it can also be used as juice. In Malaysia, herbs are also used as a traditional medicine to treat various diseases such as diabetes, skin disease and headache. Recently, Zingiberaceae is known as one of the largest family of the Monocotyledon group of flowering plants containing various medicinal and herbal species. Some of the species that belong to the Zingiberaceae family are Zingiber zerumbet, Curcuma longa, Alpinia galanga and Boesenbergia rotunda. Boesenbergia rotunda is locally known as Temu kunci. They are also known as the Chinese Key, Fingerroot, Krachai, and Krachai-Dang [1]. Boesenbergia rotunda is one of 47 genera and approximately 1000 species of Zingiberaceae [2]. It was previously categorised under the Kaempferia genus by Baker [3]. However, it is currently classified under Boesenbergia [3]. B. rotunda is a herbaceous plant with a height of between 15 and $40 \mathrm{~cm}$. The blade of the leaves is wide and green in colour, while the sheath of the leaves is red. The inflorescences were formed within the apical leaf sheaths [4].

In many Asian countries, such as Malaysia, Thailand, Indonesia, India and China, Boesenbergia rotunda is used as a condiment in foods such as curry and soup to promote appetite due to its aromatic flavour [3]. Temu kunci was also used to treat diseases such as rheumatism, muscle pain, febrifuge, gout, gastrointestinal disorders, flatulence, carminative, stomach ache, dyspepsia, and peptic ulcer [5]. In Indonesia, B. rotunda was used as a traditional "jamu", that made from root, bark, flower, seed, leaf, and fruit to prevent leukorrhea-thin and milky white vaginal discharge for teen girls. Besides that, the previous study reported that $B$. rotunda could be used as a wound healing as the crude extract of B. rotunda significantly stimulated wound contraction, compared with pure petroleum gel [6]. Another important discovery is the extract of $B$. rotunda can be used as a nutraceutical or nutricosmetic material to improve human skin hydration, gloss, and wrinkles [7]. Bosenbergia rotunda extract has also been reported to have a high potential to be developed as a natural antifungal to reduce the spoilage of vegetables [8]. This plant has also been stated to be used as anti-inflammatory, antibacterial, antifungal and antioxidant because it contains essential oil and flavonoids [9].

Due to its potential as an important herbal plant, a continuous supply of this species is needed to ensure that human beings can continue to consume and benefit from this medicinal herb. A proper method of cultivation is needed to maintain the herbal plant resource and increase the quality and production of the raw material [10]. In poor agricultural practices, the herbal species cultivation method is considered to be one of the most critical aspects of herbal planting[11]. Therefore, soil with good water holding capacity and aeration is suitable for use as a growing medium for ginger plants [12]. Besides, the soil should be loose, brittle and offer minimal resistance to the development of rhizome for higher yields [12].

Currently, little information is known about the cultivation of $B$. rotunda in order to improve their growth and yield quality. Therefore, the study of the appropriate growing medium of $B$. rotunda appears to be an essential task for the cultivation of $B$. rotunda. Thus, objective of this study was to observe the effect of the different growing medium combination on the growth and yield of Boesenbergia rotunda.

\subsection{Materials and Methods}

An experiment was conducted at Glass house and Nursery Complex, International Islamic University Malaysia, Kuantan campus. Two old months of $B$. rotunda seedling was used as a planting material. The combination of Topsoil, Peat, Sand and chicken manure with four different ratios was used as a planting medium. The mixtures were placed in a $16 \times 16$ inches polybag. The potted plants were arranged in a randomised complete block design (RCBD) with five replicates. Potted plants were watered daily, and weeds were manually controlled. Maximising the development of $B$. rotunda, an addition of 15 g NPK fertiliser, was added to all treatments every four weeks after 14 days of planting. Plants were harvested five months after planting. Parameters such as plant height, number of leaves, number of tillers, fresh and dry weight of shoots and fresh and dry weight of rhizomes have been recorded. Data were statistically analysed using the Statistic Analysis System (SAS) version 9.2 packages. The least significant difference (LSD) was used to analyse the significant mean effects of treatment.

\subsection{Result and Discussion}

Based on the analysis from the present study, there was no significant effect of planting medium on plant height, number of leaves, tiller number, fresh and dry shoot weight and fresh and dry weight of Boesenbergia rotunda. However, there is still a slight difference in the measured parameters (Table 1).

Table 1. Effect of difference planting medium combination on growth performance of B. rotunda

\begin{tabular}{|c|c|c|c|c|c|c|c|}
\hline $\begin{array}{l}\text { Treatment } \\
\text { (Topsoil: Peat: Sand: } \\
\text { Chicken manure) }\end{array}$ & $\begin{array}{l}\text { Plant height } \\
(\mathrm{cm})\end{array}$ & $\begin{array}{c}\text { Leaf } \\
\text { number }\end{array}$ & $\begin{array}{c}\text { Tiller } \\
\text { number }\end{array}$ & $\begin{array}{l}\text { Shoot Fresh } \\
\text { weight (g) }\end{array}$ & $\begin{array}{l}\text { Shoot dry } \\
\text { weight (g) }\end{array}$ & $\begin{array}{c}\text { Rhizome fresh } \\
\text { weight (g) }\end{array}$ & $\begin{array}{c}\text { Rhizome dry } \\
\text { weight (g) }\end{array}$ \\
\hline $\mathrm{T} 1(1: 0: 0: 0)$ & $31.54 a$ & $47.80 \mathrm{a}$ & $6.40 a$ & $0.094 \mathrm{a}$ & $0.009 \mathrm{a}$ & $0.128 \mathrm{a}$ & $0.023 a$ \\
\hline $\mathrm{T} 2(3: 2: 1: 0)$ & $27.48 \mathrm{a}$ & $54.4 \mathrm{a}$ & $6.00 \mathrm{a}$ & $0.118 \mathrm{a}$ & $0.012 \mathrm{a}$ & $0.159 a$ & $0.024 \mathrm{a}$ \\
\hline Т3 (3:2:1:1) & $30.40 \mathrm{a}$ & $49.60 \mathrm{a}$ & $7.40 \mathrm{a}$ & $0.143 a$ & $0.017 \mathrm{a}$ & $0.193 a$ & $0.039 a$ \\
\hline $\mathrm{T} 4(2: 1: 1: 1)$ & $22.82 \mathrm{a}$ & $47.00 \mathrm{a}$ & $5.60 a$ & $0.152 \mathrm{a}$ & $0.017 \mathrm{a}$ & $0.168 \mathrm{a}$ & $0.023 a$ \\
\hline
\end{tabular}

*Means followed by the same letter within a column are not significantly difference at the $5 \%$ probability level.

In terms of plant height, the highest value was T1 with $31.54 \mathrm{~cm}$ while the lowest plant height was T4 with $22.82 \mathrm{~cm}$. The observations also agree with the results reported by the previous study where the height of the $B$. rotunda plant in the media combination of black soil and sand was delayed, and the height decreased after ten months of planting [1]. They also claimed that the highest shoot of B. rotunda was achieved in a growing medium containing a combination of red and black soil. This result was also supported by the experiment conducted before, which showed that the composition of the media alone did not significantly influenced on all the parameters of growth and yield of red ginger rhizome [13]. 
Besides that, T2 produced the highest number of leaves (54), while T4 produced the lowest (47). The findings of the present study showed that plant grown in media consisting of peat moss produced the highest leaves number compared to topsoil alone. Leaves are one of the organs that play a vital role in the process of photosynthesis, where the highest number of leaves will increase the photosynthetic rate of the plant. This finding is in keeping with previous research where Antirrhinum majus has the highest number of leaves when grown in a medium consisting of peat moss [14].

The number of tillers ranged from 6 to 7 per plant in all the examined treatments. However, the planting medium containing mo re chicken manure produced a higher number of tillers compared to those without chicken manure. In line with the previous study, the application of organic manure as a growing medium for ginger species increased the uptake of nutrient by plant root [15].

The result show treatment of $\mathrm{T} 4$ resulted in the highest amount of fresh and dry shoot weight. The fresh and dry weights of T4 were $0.152 \mathrm{~g}$ and $0.017 \mathrm{~g}$ respectively. The previous study also claimed that the different soil mixture did not have an adverse effect on $B$. rotunda biomass [1]. In addition, the planting medium containing an adequate supply of nutrients is good for plants to achieve optimum growth and development [14].

Although there were no significant differences in fresh and dry rhizome weight, there is still a slight difference in the measured parameter. Based on available data, T3 containing the highest organic matter produced the most fresh $(0.193 \mathrm{~g})$ and dry $(0.039 \mathrm{~g})$ weight of rhizome. The lowest fresh and dry weight of rhizome was recorded in T1, as this treatment only contains topsoil as a growing medium. According to literature, the use of organic matter has been reported to increase the yield of Zingiber zerumbet [11]

\subsection{Conclusion}

B. rotunda is a useful plant because it contains many medicinal compounds that can be used to treat many diseases. Due to its beneficial properties, many studies have been conducted to improve their growth and yield quality. In conclusion, this study did not reveal any significant differences in growth and yield of $B$. rotunda as affected by different growing medium. However, this analysis leads to some useful suggestion. Since there were no adverse effects between each treatment, it is therefore suggested that the topsoil be used as a growing medium for $B$. rotunda, as it is easily obtained and requires a lower cost of money for $B$. rotunda cultivation. Nevertheless, further research should be conducted to examine other agronomic requirements of $B$. rotunda.

\subsection{Acknowledgement}

The authors would like to express their thanks and gratitude to staff of Kuliyyah of Science, International Islamic University Malaysia (IIUM), for their assistance and support throughout the study. This research was funded by the Research Initiative Grant Scheme (RIGS15-128-0128), International Islamic University Malaysia.

\section{References}

[1] K.A. Rashid, A.B.M. Daran, N. Khalid, M. Jalil, Y.M. Yusuf and S.E. Rozali, "Effects of different quality of soil mixture on growth development of an important medicinal plant, boesenbergia rotunda", Malaysian Applied Biology, Vol. 44(3), Pp. 113-120, 2015

[2] S. Atun, H. Sri, A. Rakhmawati, "Potential bioactive compounds isolated from boesenbergia rotunda as antioxidant and antimicrobial agents", Pharmacognosy Journal, Vol. 10(3), Pp. 513-518, 2018.

[3] T.E. Chong, L.Y. Kee, C.C. Fei, H.C. Han and W.S. Ming, “Boesenbergia rotunda: From ethnomedicine to drug discovery. Evidence-Based Complementary and Alternative Medicine", Pp. 1-25, 2012.

[4] T.K. Lim, “Boesenbergia rotunda. In: Edible Medicinal and Non-Medicinal Plants”, Springer, Cham, 2016.

[5] E.C. Tan, S.A. Karsani, G.T. Foo, S.M. Wong, N.A. Rahman, N. Khalid, R. Yusof, "Proteomic analysis of cell suspension cultures of Boesenbergia rotunda induced by phenylalanine: Identification of proteins involved in flavonoid and phenylpropanoid biosynthesis pathways", Plant Cell, Tissue and Organ Culture (PCTOC), Vol. 111(2), Pp. 219-229, 2012.

[6] R. Jitvaropas, S. Saenthaweesuka, N. Somparna, A. Thuppiaa, Phoolcharoenb, S.S. Waranyoo, "Antioxidant, antimicrobial and wound healing activities of Boesenbergia rotunda", Vol.7(7), Pp. 909-912, 2012.

[7] D.U. Kim, H.C. Chung, C. Kim, J.K. Hwang, "Oral intake of Boesenbergia pandurata extract improves skin hydration, gloss, and wrinkling: A randomized, double-blind,and placebo-controlled study", Journal of Cosmetic Dermatology, Pp. 1-8, 2017.

[8] Z. Zakuan, S.A. Mustapa, R. Sukor, and Y. Rukayadi, "Antifungal activity of Boesenbergia rotunda (Temu Kunci) extract against filamentous spoilage fungi from vegetables", International Food Research Journal, Vol. 25(1), Pp. 433-438, 2018.

[9] A. Chahyadi, R. Hartati, K.R. Wirasutisnaa, and El-fahmi, "Boesenbergia pandurata Roxb., an Indonesian medicinal plant: phytochemistry, biological activity, plant biotechnology", Procedia Chemistry, Vol. 13, Pp. 13-37, 2014.

[10] R. Shahari, N.A.P. Abdullah, G. Saleh, A. Selamat and R. Go, "Early growth and plant performance of Molineria colla species grown under different shade levels and media compositions", International Journal of Advanced Research, Vol. 4(2), Pp. 1171-1185, 2016.

[11] N. Munawer, R. Shahari, "Early growth of Zingiber zerumbet (1.) smith as affected by different organic fertilizers and harvesting times", International Journal of Recent Technology and Engineering (IJRTE), Vol. 7(6S5), 2019

[12] T. Tadesse \& Kifle, Asfaw \& Tefera, Alye \& Abate, Sinedu \& Sima, Brihanu \& Astatike, Abrham \& Habte, Tefaye \& Samuel, Akalewold, "Ginger (Zingiber oficinale rosec.): production, postharvest handling, processing and marketing-A Comprehensive Extension Package Manual", 2015. Doi: 10.13140/RG.2.1.3034.7361.

[13] S. Soeparjono, "The effect of media composition and organic fertilizer concentration on the growth and yield of red ginger rhizome (Zingiber officinale Rosc.)", Agriculture and Agricultural Science Procedia, Vol. 9, Pp. 450-455, 2016.

[14] T. Mehmood, W. Ahmad, K.S. Ahmad, J. Shafi, M.A. Shehzad, M.A. Sarwar, "Comparative effect of different potting media on vegetative and reproductive growth of floral shower (Antirrhinum majus L.)”, Universal Journal of Plant Science, Vol. 1(3), Pp. 104-111, 2013

[15] A.Y. Samanhudi, B. Pujiasmanto, M. Rahayu, "Effect of organic manure and arbuscular mycorrhizal fungi on growth and yield of young ginger (Zingiber officinale Rosc.)”, Journal of Agriculture and Veterinary Science, Vol. 7(5), Pp. 1-5, 2014. 